\title{
Chemistry and physical properties of estolides
}

\author{
By Terry A. Isbell*
}

\author{
United States Department of Agriculture, Agriculture Research Service, \\ National Center for Agricultural Utilization Research, 1815 N. University St. Peoria, \\ Illinois 61529 \\ ( ${ }^{\star}$ Corresponding author: terry.isbell @ ars.usda.gov)
}

\section{RESUMEN}

\section{Propiedades físicas y químicas de los estólidos}

Los estólidos son una familia de compuestos sintetizados a partir de aceites hidroxilados como los de ricino o lesquerella o mediante la condensación de ácidos grasos sobre el doble enlace de un segundo ácido graso insaturado. Los estólidos de ricino y lesquerela se derivan tanto de sus triglicéridos como de sus ácidos grasos libres empleándose el residuo hidroxilo para formar los ésteres estólidos de los mismos. Los triglicéridos estólidos tienen puntos de fluidez crítica de entre 9 y -36으 y baja estabilidad, con tiempos de oxidación en recipiente vacío a presión (RPVOT) de entre 29 y 52 minutos incluso con la adición de un $1 \%$ de una mezcla antioxidante a las muestras. Estas propiedades contrastan con las de los estólidos de ácido lesquerólico y ricinoleico, que poseen puntos críticos de fluidez mucho más bajos (de -36 a -54). Los estólidos derivados mediante la condensación de ácido oleico con otros ácidos grasos por catálisis ácida pueden realizarse con buen rendimiento y presentan un rango bastante amplio de propiedades físicas. A este respecto son de bastante interés los estólidos de ácido oleico esterificados con ácidos grasos saturados los cuales presentan tanto buen comportamiento a bajas temperaturas (puntos de fluidez crítica de $-5^{\circ}$ a $-39^{\circ} \mathrm{C}$ ) como buena estabilidad oxidativa. Los estólidos de los ácidos grasos del aceite de prado (Limnanthes alba) no presentan buenas propiedades de lubricación a baja temperatura pero su uso está muy extendido en cosmética, donde muestran buenas propiedades como agente hidratante.

PALABRAS-CLAVE: Ácido oleico - Lesquerella - Propiedades físicas - Ricino - Síntesis.

\section{SUMMARY}

\section{Chemistry and physical properties of estolides}

Estolides are a developing class of natural and synthetic compounds that have been synthesized from hydroxy oils like castor and lesquerella or by the condensation of fatty acids across the olefin of a second fatty acid. Castor and lesquerella estolides are derived from either their triglycerides or their free fatty acids utilizing their hydroxyl moiety to establish the estolide bond. The triglyceride estolides have pour points of 9 to $-36^{\circ} \mathrm{C}$ but suffer poor oxidative stability with RPVOT times of $29-52$ minutes even with $1 \%$ of an anti-oxidant package incorporated into the samples. In contrast to the triglyceride estolides of castor and lesquerella, the estolides from lesquerolic and ricinoleic acids have very good pour points of -36 to $-54^{\circ} \mathrm{C}$. Estolides derived from the acid catalyzed condensation of oleic acid with a variety of fatty acids can be made in good yield and posses a wide range of physical properties. Of particular interest are the saturated capped estolides of oleic that have both good low temperature properties (pour point -5 to $-39^{\circ} \mathrm{C}$ ) and good oxidative stability. Estolides from meadowfoam fatty acids do not have good low temperature properties but have been extensively used in cosmetics where they provide good moisturizing properties.

KEY-WORDS: Castor - Estolide - Lesquerella - Oleic acid - Physical Properties - Synthesis.

\section{INTRODUCTION}

Estolides are natural and synthetic compounds derived from fats and oils. The estolide structure is identified by the secondary ester linkage of one fatty acyl molecule to the alkyl backbone of another fatty acid fragment. Figure 1 describes the general nomenclature of an estolide where the internal ester linkage is the estolide bond position. The Estolide Number (EN) is defined as $n+1$ indicating the extent of oligomerization of the molecule. Estolides can be free acids, esters or found within a triglyceride structure. The later form of estolide occurs naturally in the genus lesquerella where the species lesquerella auriculata produces up to $96 \%$ of its seed oil as estolides (Hayes et al., 1995a). Triglyceride estolides have been synthesized from castor and lesquerella oils and used in a wide range of lubricant applications and when the estolide is dehydrated the resulting product is a drying oil (Penoyer et. al., 1954). Estolides synthesized from unsaturated fatty acids have introduced a wide range of new estolide structures based on the position of the original olefin of the starting fatty acid (Isbell et. al., 2001). Estolides based on these sources have been used in cosmetics and industrial applications. This review will discuss the synthesis and physical properties of this unique class of fatty acid derivative.

\section{GLYCERIDE ESTOLIDES}

\subsection{Natural estolides}

Although glyceride estolides, polyacyl glycerides, are not unexpected components from hydroxy and epoxy containing oils their natural presence are not 


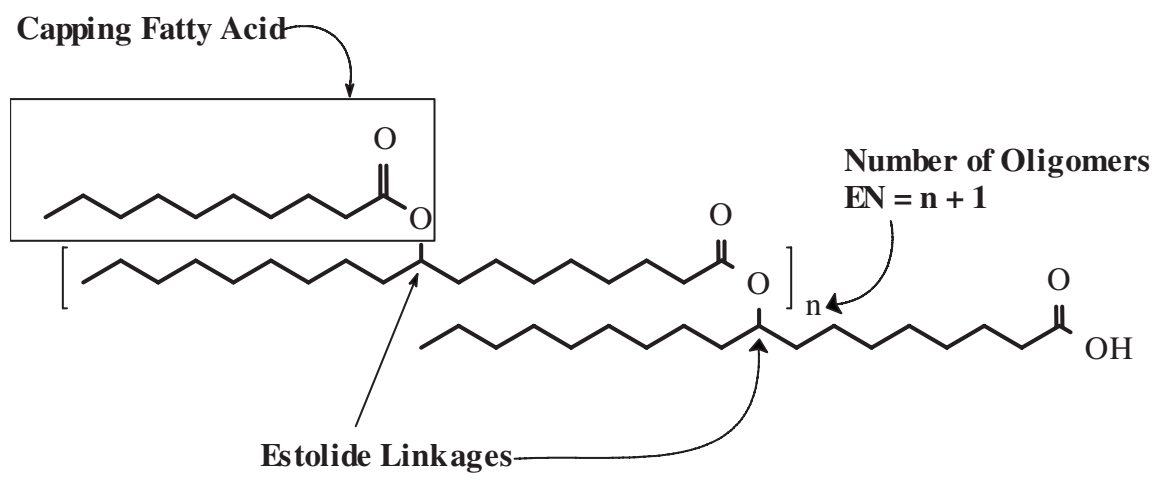

Figure 1.

Estolide Nomenclature: Free acid estolide capped with a C10 saturated fatty acid with an estolide number of $2(\mathrm{EN}=2)$.

widely described in the literature and none of these unique oils has ever reached a commercial scale. The literature reports estolides from eleven different plant genus: Cardamine, Chamaepeuce, Dimorphotheca, Heliophila, Holarrhena, Lesquerella, Monnina, Nerium, Sapium, Sebastiana and Trewia. Of this list a few unique and promising seed oils should be discussed. Heliophila amplexicaulis (Platner et. al., 1979) is a member of the mustard family collected in Spain and produces a seed oil rich in lesquerolic acid (30\%) where all of the hydroxy groups are found esterified into estolides. Interestingly, the Heliophila amplexicaulis estolide capping fatty acid group is erucic acid where the other seed oil estolides mentioned in the group above all have fatty acid groups of 18 carbons or less as the predominant capping fatty acid. Recent interest in the utilization of the invasive shrub Sapium sebiferum (Chinese tallow) may provide a source for an allenic estolide, 8-(2(E), 4(Z)-decadienoyl)-5( $E)$, 6-(E)-octadecadienoic acid, (Aitzetmuller et. al., 1992; Payne-Wahl and Kleiman 1983). The last member of this unique group of seed oils are the estolides derived from lesquerella auriculata. This seed contains $32 \%$ oil of which $96 \%$ of the oil is found as an estolide (Hayes et. al. 1995a; Kleiman et. al., 1972). Unfortunately, the availability of these natural estolides has limited the quantity of oil and physical properties of these novel materials have not been reported.

\subsection{Synthetic glyceride estolides}

The hydroxy functionality of castor and lesquerella oil provides a useful site to conduct esterification reactions where the resulting product is an estolide. The hydroxyl moiety being a relative reactive species can be easily esterified on the intact triglyceride without degradation of the glyceride molecule. Early work by Penoyer et al., (1954) demonstrated the feasibility of synthesizing estolides via a high temperature esterification reaction at $250^{\circ} \mathrm{C}$ under a $\mathrm{CO}_{2}$ sparge. This estolide was then directly dehydrated under vacuum at $260^{\circ} \mathrm{C}$ into a conjugated oil that was used for making drying films. In this case the estolides were not characterized or their physical properties determined. Erciyes et al., (1991) provided additional details to the synthesis of triglyceride estolides where they explored the rates of estolide formation from castor oil when condensed with oleic acid between $200^{\circ} \mathrm{C}$ to $250^{\circ} \mathrm{C}$. Erdem et al., (1994 and 1995) explored the use of Lewis acid catalysts like tin chloride and cobalt chloride in reactions of castor oil with oleic acid but the high reaction temperatures $\left(200^{\circ} \mathrm{C}\right.$ to $\left.250^{\circ} \mathrm{C}\right)$ studied for the cobalt catalyzed reaction provided no real advantage to those reactions performed in the absence of catalyst. However, Erdem's work did provide insight into the reaction mechanism. Later work on the kinetics of the esterification reaction of castor with lauric acid in the presence of various Lewis acid catalysts by Kulkarni et al., (2003) demonstrated that n-butyl titanate was an effective catalyst for the formation of estolide. When $4 \%$ catalyst was employed, at $185^{\circ} \mathrm{C}$, a $68 \%$ conversion to triglyceride estolide was obtained in 6 hours. The reaction was first order in both fatty acid and hydroxy oil.

A patent by Lawate (1995) describes the synthesis of triglyceride estolides for castor and lesquerella with heptanoic, isostearic, adipic and fumaric acids as the capping fatty acid using p-toluenesulfonic acid as the catalyst (Figure 2). A reaction temperature of $150^{\circ} \mathrm{C}$ was used to azeotropically remove the water of esterification. All of the estolide products synthesized were run at stoichiometry such that the triglyceride hydroxyl groups would all be esterified to estolide. The lesquerella triglyceride estolide products were then evaluated for their thickening performance by the change in viscosity in admixtures with a high oleic vegetable oil ( $80 \%$ Oleic). Figure 3 graphs the percent increase in viscosity of the high oleic vegetable oil when 5, 20 and 30\% triglyceride estolide was added. Fumaric acid, a diacid, had the largest impact under the conditions studied where a $5 \%$ incorporation of estolide produced a $23 \%$ increase in the solution viscosity. The other diacid reported, adipic, had similar thickening capabilities where a $5 \%$ mixture gave a $17 \%$ increase in viscosity at $40^{\circ} \mathrm{C}$. The monoacid, isostearic, provided no apparent increase in viscosity beyond simple thickening by mixing two fluids, one of low viscosity with one of high viscosity (5\% mixture gave a $5 \%$ increase in viscosity).

Later Isbell and Cermak (2002) synthesized a series of triglyceride estolides from both castor 


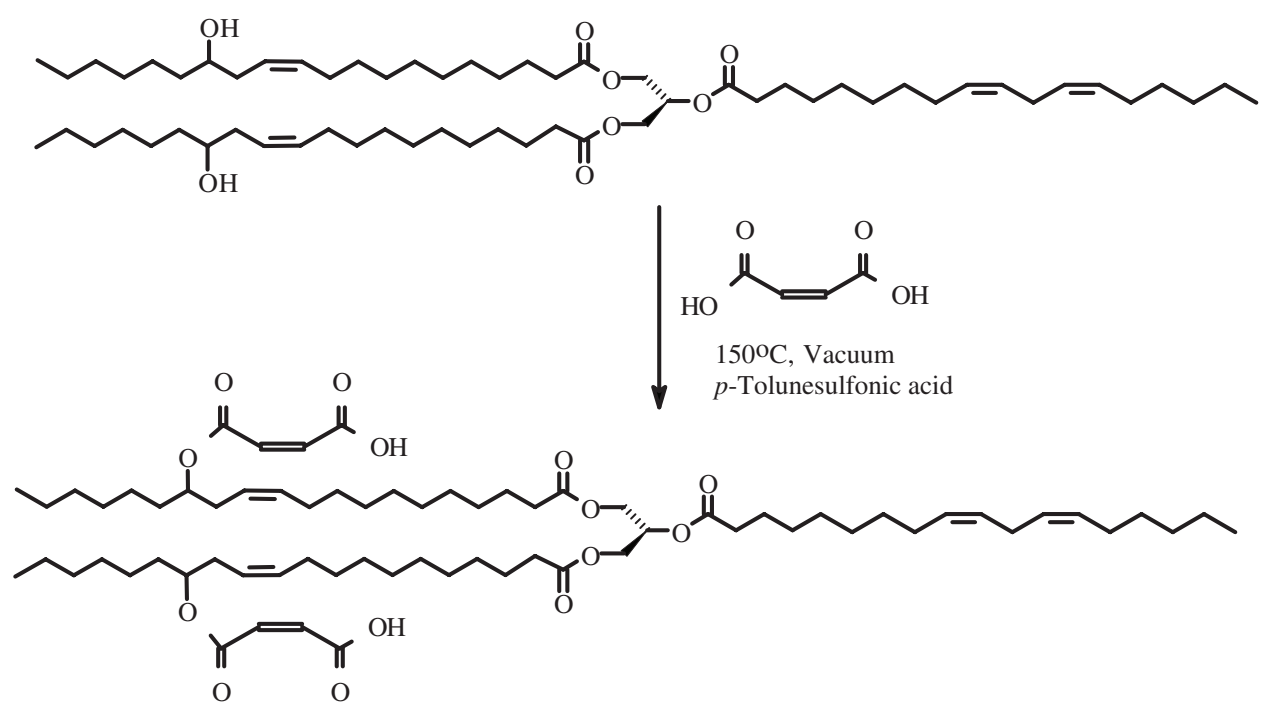

Figure 2

Synthesis of lesquerella triglyceride estolides (Lawate 1995).

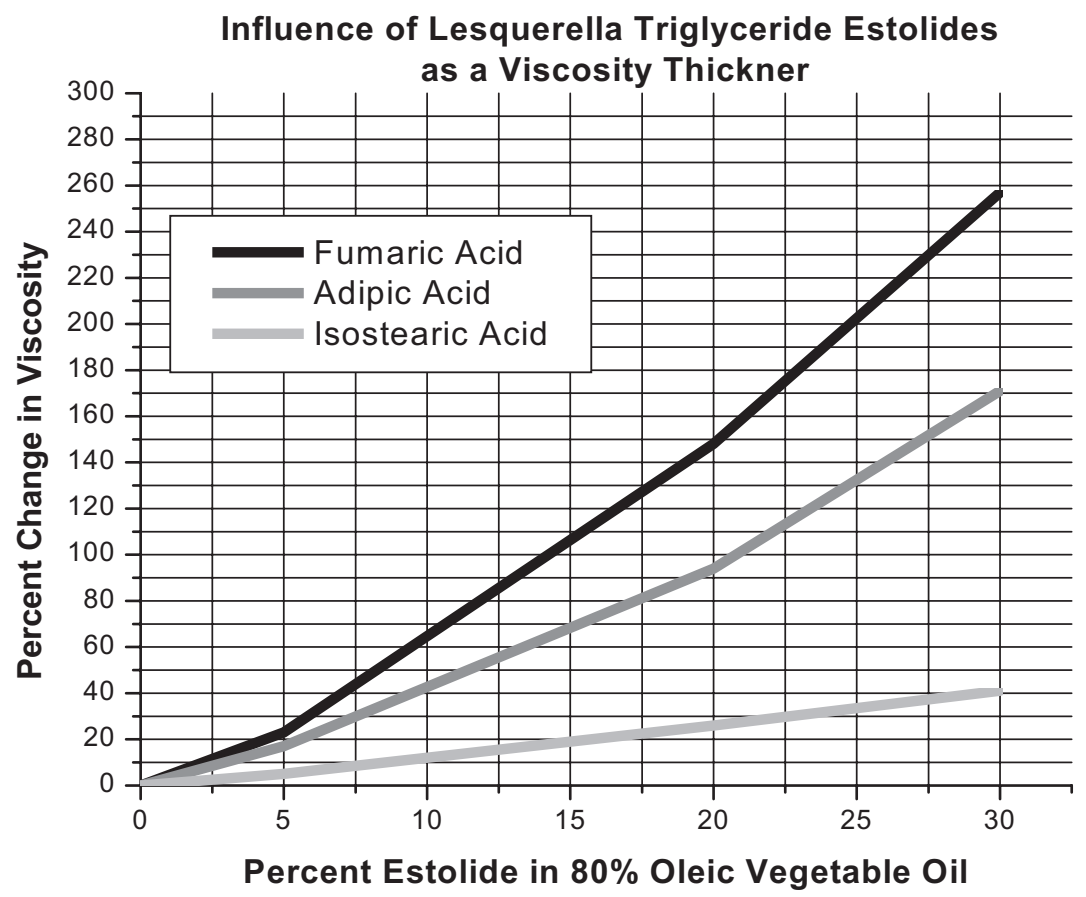

Figure 3

Influence of lesquerella triglyceride estolide on high oleic vegetable oil viscosity. Data summarized from Lawate (1995).

and lesquerella oils and compared their physical properties (Isbell et. al., 2006). Their work demonstrated (Figure 4) that mono-, di- and fullycapped triglyceride estolides could be synthesized from both castor and lesquerella oils with oleic acid as the capping fatty acid. Table 1 outlines the general reaction conditions explored where all reactions were run neat. The bulk of the reactions used vacuum to remove the water of esterification but the reaction could also be performed under nitrogen (Entry L-C, Table 1). Although reactions can be performed at lower temperature $\left(100^{\circ} \mathrm{C}\right)$ the reaction nears completion in 24 hours when the reaction exceeds $175^{\circ} \mathrm{C}$ (Entry L-D, Table 1). If the temperature is pushed to $250^{\circ} \mathrm{C}$ increase in the undesirable dehydration product, diene, is observed (Entry L-E, Table 1). Stoichiometry of the capping fatty acid with respect to the oil dictates the extent of estolide formation and capping of individual hydroxyl groups on the triglyceride is observed (Entries C-A, C-B and C-D, Table 1). For lesquerella oil, a fully capped estolide has an 
Table 1

Synthesis of estolides from oleic acid with Lesquerella and Castor oils

\begin{tabular}{cccccccc}
\hline Entry & $\begin{array}{c}\text { FA } \\
\text { Equiv }^{2} .\end{array}$ & Atmosphere & $\begin{array}{c}\text { Temp. } \\
\left({ }^{\circ} \mathbf{C}\right)\end{array}$ & $\begin{array}{c}\text { Time } \\
\mathbf{( h )}\end{array}$ & $\begin{array}{c}\text { Conversion (\%) } \\
\text { to estolide }\end{array}$ & $\begin{array}{c}\text { EN }^{3} \text { Crude } \\
(\mathbf{N M R})\end{array}$ & $\begin{array}{c}\text { Diene } \\
(\mathbf{m o l e} \%)^{4}\end{array}$ \\
\hline L-A & 1 & Vacuum & 200 & 24 & 56 & 1.06 & 0.0 \\
L-B & 3 & Vacuum & 200 & 24 & 100 & 1.89 & 0.0 \\
L-C & 2 & Nitrogen & 200 & 24 & 77 & 1.45 & 0.0 \\
L-D & 2 & Vacuum & 175 & 24 & 97 & 1.84 & 0.0 \\
L-E & 2 & Vacuum & 250 & 24 & 100 & 1.89 & 3.5 \\
L-F & 2 & Vacuum & 200 & 12 & 100 & 1.89 & 0.0 \\
C-A & 1 & Vacuum & 200 & 24 & 37 & 0.98 & 0.9 \\
C-B & 2 & Vacuum & 200 & 24 & 59 & 1.58 & 0.0 \\
C-C & 3 & Vacuum & 200 & 24 & 92 & 2.46 & 3.2 \\
C-D & 4 & Vacuum & 200 & 24 & 100 & 2.67 & 0.3 \\
\hline
\end{tabular}

Data from Isbell and Cermak (2002). ${ }^{1} \mathrm{~L}$ is Reactions run with lesquerella oil and $\mathrm{C}$ are reactions run with castor oil. ${ }^{2}$ Mole equivalents of oleic acid based on the moles of lesquerella. ${ }^{3} \mathrm{EN}$ values were determined by NMR. A fully capped lesquerella estolide has an EN of 1.89 and a fully capped castor estolide has an EN of $2.67 .{ }^{4}$ Mole percent determined by GC.

EN $=1.89$ and for castor oil a fully capped estolide has an $E N=2.67$. These theoretical $E N$ values are based on $60 \%$ hydroxy fatty acid concentration in lesquerella and $90 \%$ hydroxy fatty acids in castor oil. Castor oil full-capped estolides require additional excess equivalents of capping fatty acid to fully esterify the hydroxy moieties probably due to the developing steric hindrance of the triglyceride molecule once two estolide groups are already formed. When smaller fatty acid groups are used to form the triglyceride estolides (C2-C4), anhydrides must be employed along with reduced temperature $\left(60^{\circ} \mathrm{C}\right)$. When mid chain (C6-C12) fatty acid groups are used for capping, tin(II) 2-ethylhexanoate catalyst and intermediate temperatures of $130^{\circ} \mathrm{C}$ are used to avoid boiling off of the capping fatty acid during the course of the reaction (Isbell et. al., 2006). When fatty acid capping groups longer than $\mathrm{C} 12$ are used the reactions can by run neat under vacuum at $200^{\circ} \mathrm{C}$.
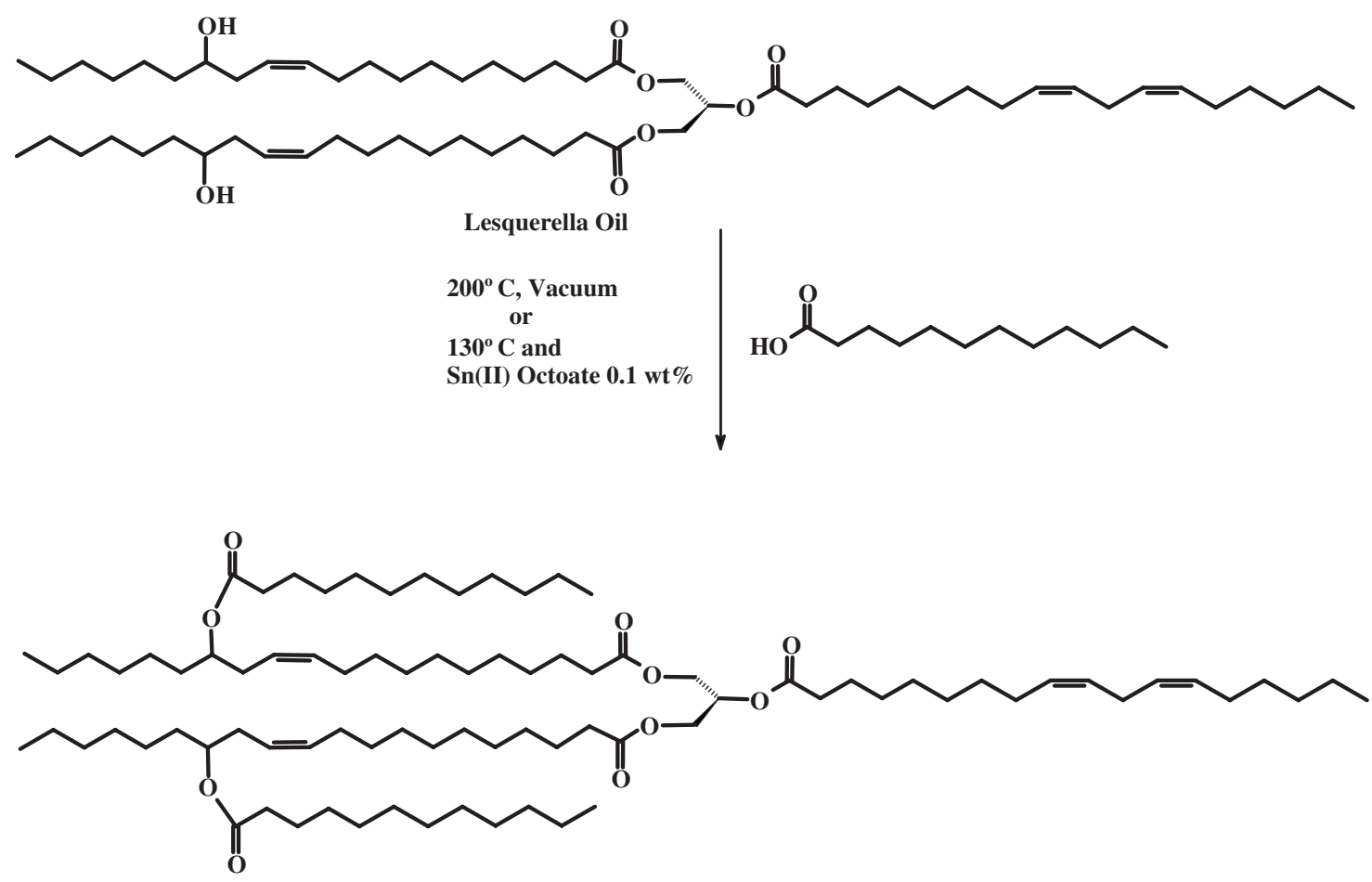

Decanoyl Fully Capped Lesquerella Triglyceride Estolide

Figure 4

Synthesis of triglyceride estolides from lesquerella under vacuum (Isbell et. al., 2002). 
A series of saturated $C 2$ to $C 18$ and 18:1 capping fatty acids were used to mono- and fully-cap castor and lesquerella oils and their physical properties are reported in Tables 2 and 3 (Isbell et. al., 2006). The starting hydroxy oils, lesquerella and castor, have pour points of $-21^{\circ} \mathrm{C}$ and $-15^{\circ} \mathrm{C}$, respectively. Because of the hydroxy group in these oils and the resultant hydrogen bonding, both of these oils have high viscosities at $40^{\circ} \mathrm{C}, 127.7 \mathrm{cSt}$ for lesquerella and $260.4 \mathrm{cSt}$ for castor oil. This high viscosity limits their use in many lubricant and fuel applications. When estolides are formed at the hydroxyl positions the pour point as well as the viscosity can be improved. The fully capped estolides $\mathrm{C} 2-\mathrm{C} 10$ for lesquerella and $\mathrm{C} 2-\mathrm{C} 12$ for castor gave lower pour points than the corresponding mono-capped triglyceride estolide. The larger saturated capping groups (C12-C18 for lesquerella and $\mathrm{C} 14-\mathrm{C} 18$ for castor) gave lower pour points for the mono-capped series than the full-capped estolides. The longer chain capping fatty acids apparently have sufficient alkyl stacking interactions due to the unhindered exposure of the alkyl portion of the capping fatty acid to increase cloud and pour points. The shorter chain fatty acid capping groups improved the pour points for the underivatized oils by disrupting alkyl stacking interaction of the triglyceride itself. This effect is not observed in the acetate estolides indicating that the very short chain length is not capable of providing disruption of the alkyl stacking interactions. The acetate group would not be of sufficient length to sweep the entire length of the alkyl chain beyond the hydroxy functionality. Of particular note is the fact that the hexanoic capping group gave the lowest pour points in all the estolides series where the length of the hexanoyl chain would be capable of completely sweeping the alkyl chain but not of sufficient length to expose its own backbone to alkyl stacking interactions. As a result, the minimum pour points observed were $-36^{\circ} \mathrm{C}$ for hexanoic fullycapped lesquerella and $-45^{\circ} \mathrm{C}$ for hexanoic capped castor triglyceride estolides.

The two main factors in this series of homologous compounds that impact viscosity are hydrogen bonding by the hydroxyl groups and the steric bulk of the molecules. Intermolecular hydrogen bonding between the hydroxy triglycerides increases the steric bulk of the solution by creating weakly associated dimers, trimers, etc. of the original triglycerides, therefore increasing the viscosity of the oil. In all cases, the fullcapped triglyceride estolides have lower viscosities for all chain-lengths than the mono-capped estolides

Table 2

Physical Properties of Lesquerella triglyceride estolides

\begin{tabular}{|c|c|c|c|c|c|c|}
\hline $\begin{array}{l}\text { Capping } \\
\text { Fatty Acid }\end{array}$ & $\begin{array}{c}\text { Capping } \\
\text { Extent }\end{array}$ & $\begin{array}{l}\text { Estolide } \\
\text { Number }\end{array}$ & $\begin{array}{c}\text { Pour Point } \\
\left({ }^{\circ} \mathrm{C}\right)\end{array}$ & $\begin{array}{l}\text { Cloud Point } \\
\left({ }^{\circ} \mathrm{C}\right)\end{array}$ & $\begin{array}{c}\text { Viscosity @ } \\
40^{\circ} \mathrm{C} \text { (cSt) }\end{array}$ & $\begin{array}{l}\text { Viscosity @ } \\
100^{\circ} \mathrm{C} \text { (cSt) }\end{array}$ \\
\hline None & NA & NA & -21 & -22 & 127.7 & 15.2 \\
\hline C2:0 & Mono & 0.90 & -21 & $>$ r.t. & 92.8 & 14.6 \\
\hline C2:0 & Full & 1.70 & -30 & -18 & 79.7 & 14.2 \\
\hline C4:0 & Mono & 0.88 & -27 & $<-27$ & 86.7 & 14.4 \\
\hline C4:0 & Full & 1.50 & -33 & -30 & 74.7 & 13.9 \\
\hline C6:0 & Mono & 0.78 & -33 & $>$ r.t. & 103.0 & 15.9 \\
\hline C6:0 & Full & 1.23 & -36 & $>$ r.t. & 87.9 & 15.2 \\
\hline C8:0 & Mono & 0.75 & -27 & -25 & 115.7 & 15.1 \\
\hline C8:0 & Full & 1.41 & -33 & -27 & 76.0 & 14.8 \\
\hline C10:0 & Mono & 0.66 & -27 & -26 & 118.5 & 17.2 \\
\hline C10:0 & Full & 1.51 & -30 & -17 & 99.9 & 16.7 \\
\hline C12:0 & Mono & 1.00 & -27 & -23 & 110.8 & 17.4 \\
\hline C12:0 & Full & 1.60 & -18 & -28 & 101.0 & 17.2 \\
\hline C14:0 & Mono & 1.29 & -18 & 1 & 129.9 & 19.2 \\
\hline C14:0 & Full & 1.46 & 3 & 21 & 118.6 & 18.4 \\
\hline C16:0 & Mono & 0.83 & 0 & 15 & 135.2 & 20.5 \\
\hline C16:0 & Full & 1.75 & 6 & 27 & 114.2 & 18.7 \\
\hline C18:0 & Mono & 1.46 & 9 & 28 & 137.4 & 20.5 \\
\hline C18:0 & Full & 1.75 & 24 & 45 & Solid & 34.3 \\
\hline C18:1 & Mono & 0.97 & -27 & -16 & 119.6 & 18.7 \\
\hline C18:1 & Full & 1.56 & -27 & -16 & 95.1 & 17.0 \\
\hline
\end{tabular}

Data from Isbell et. al., (2006). 
Table 3

Physical properties of castor triglyceride estolides

\begin{tabular}{ccccccc}
\hline $\begin{array}{c}\text { Capping } \\
\text { Fatty Acid }\end{array}$ & $\begin{array}{c}\text { Capping } \\
\text { Extent }\end{array}$ & $\begin{array}{c}\text { Estolide } \\
\text { Number }\end{array}$ & $\begin{array}{c}\text { Pour Point } \\
\left({ }^{\circ} \mathbf{C}\right)\end{array}$ & $\begin{array}{c}\text { Cloud Point } \\
\left({ }^{\circ} \mathbf{C}\right)\end{array}$ & $\begin{array}{c}\text { Viscosity @ } \\
\mathbf{4 0}{ }^{\circ} \mathbf{C}(\mathbf{c S t})\end{array}$ & $\begin{array}{c}\text { Viscosity @ } \\
\mathbf{1 0 0} \mathbf{0}^{\circ} \mathbf{C} \text { (cSt) }\end{array}$ \\
\hline None & NA & NA & -15 & -34 & 260.4 & 20.1 \\
C2:0 & Mono & 0.82 & -24 & $<-24$ & 147.4 & 16.8 \\
C2:0 & Full & 2.59 & -27 & $<-27$ & 110.0 & 15.6 \\
C4:0 & Mono & 0.93 & -27 & $<-27$ & 117.4 & 15.4 \\
C4:0 & Full & 2.70 & -33 & -30 & 82.2 & 14.0 \\
C6:0 & Mono & 0.80 & -36 & $<-36$ & 133.0 & 19.4 \\
C6:0 & Full & 1.67 & -45 & $<-45$ & 79.0 & 17.0 \\
C8:0 & Mono & 0.98 & -21 & $<-21$ & 203.0 & 21.1 \\
C8:0 & Full & 2.54 & -36 & $<-36$ & 105.9 & 16.8 \\
C10:0 & Mono & 1.04 & -27 & $<-27$ & 183.8 & 21.0 \\
C10:0 & Full & 2.34 & -36 & $<-36$ & 91.8 & 16.2 \\
C12:0 & Mono & 0.92 & -27 & $<-27$ & 193.1 & 21.4 \\
C12:0 & Full & 2.36 & -33 & $<-33$ & 120.0 & 19.1 \\
C14:0 & Mono & 1.11 & -24 & -17 & 223.4 & 25.6 \\
C14:0 & Full & 2.69 & -18 & -7 & 155.9 & 23.2 \\
C16:0 & Mono & 0.81 & -18 & -3 & 220.6 & 24.1 \\
C16:0 & Full & 2.69 & 3 & 21 & 177.8 & 26.1 \\
C18:0 & Mono & 2.10 & 9 & 27 & 226.8 & 26.6 \\
C18:0 & Full & 2.42 & 18 & 24 & 174.5 & 25.7 \\
C18:1 & Mono & 1.55 & -33 & $<-50$ & 186.9 & 23.5 \\
C18:1 & Full & 2.69 & -27 & -27 & 131.8 & 21.9 \\
\hline
\end{tabular}

Data from Isbell et. al., (2006).

even though the size of the molecule is much larger. Capping of the hydroxyl moiety reduces or eliminates the hydrogen bonding and consequently reduces the viscosity of the oil. The viscosity trend across the chainlength series follows a relationship where increasing viscosity is correlated to increasing chain length.

The oxidative stability of these estolides is poor due to the inherent unsaturation remaining in the triglyceride molecule even after the estolide is formed. As a result, Rotating Pressure Vessel Oxygen Testing (RPVOT) of the original oils and the series of estolides from both castor and lesquerella gave poor results (RPVOT times $\sim 15$ minutes). Even when oxidative stability agents were added RPVOT times could only be improved to about 100 minutes with $2 \%$ additive (Isbell et. al., 2006).

\section{ESTOLIDES FROM FATTY ACIDS}

\subsection{Estolides from hydroxy fatty acids}

The potential to synthesize estolides from the hydroxy oils is not limited to the triglyceride structure only. The fatty acids from the hydrolyzed oils provide even greater opportunity to develop industrial materials with enhanced performance properties. The ability to modify the fatty acid functionality with esters of various chain lengths and branching, along with the potential to build up incremental molecular weights through homo-polymerization, provides a good route to making molecules with targeted physical properties. Estolides have been reported in the literature from castor oil for quite some time (Meyer 1897) and the homopolymerization extensively studied by a variety of wet chemical means (Modak and Kane 1965). Modak and Kane's work clearly demonstrated the formation of polyestolide from castor oil fatty acids by the homopolymerization reaction at $202^{\circ} \mathrm{C}$ gave an acid value of $38 \mathrm{mg} \mathrm{KOH} / \mathrm{g}$ Oil. Based on the molecular weight of ricinoleic acid this molecule would have contained 5 ricinoleate groups thus $\mathrm{EN}=4$ and a molecular weight of $1,476 \mathrm{~g} / \mathrm{mole}$. Modak and Kane's work was most interested in the decomposition of estolide into conjugated dienes unfortunately; the estolide fraction was not characterized for its physical properties. However, work by Teeter et al., (1953) describes the synthesis of estolide esters from hydroxystearic 
acid obtained by the hydrogenation of ricinoleic acid. Hydroxystearic acid was first esterified with various alcohols and the resulting esters reacted with an acid anhydride or acid chloride to form the corresponding estolide. Teeter reports both viscosity and pour point data on these estolides with an acetyl capped estolide 2-ethylhexyl ester providing the lowest pour point of $-63^{\circ} \mathrm{C}$ (Table 4).

Lipases have been used to synthesize estolides and esters from lesquerolic acid (Hayes and Kleiman 1995b) and estolide yields reached $62 \%$ after 65 hours using Pseudomonas sp. lipase where the estolide formed was $>80 \%$ monoestolide. Subsequent conversion to oleyl and decyl esters was readily accomplished and melting points of $-19^{\circ} \mathrm{C}$ was reported for both of these derivatives along with viscosity indices of 150-302. Hayes went on to write a review for the use of lipase catalysis (Hayes 1996) with a few examples of estolides formed from lesquerella and castor fatty acids. Kiatsimkul et al., (2008) used C. rugosa or C. antartica lipases to synthesize homo-oligomeric estolides of ricinoleic acid both under vacuum and atmospheric pressures at $60^{\circ} \mathrm{C}$. The reaction required 5 days to yield $\sim 50 \%$ estolide which consisted of dimmers and trimers. These estolides were later used to open epoxidized soybean oils to make polyols.

Lesquerella and castor free acid estolides were also produced (Figure 5) from a variety of capping fatty acids and their physical properties compared (Cermak et. al., 2006). The estolides were synthesized from castor and lesquerella oils corresponding hydroxy 2-ethylhexyl esters and capped with saturated, branch chain or unsaturated fatty acids as shown in Table 4. Both the simple oleic and the branched 2-ethylhexyl capping groups gave excellent pour points of $-54^{\circ} \mathrm{C}$ for both lesquerolic and ricinoleic estolides as their 2-ethylhexyl esters. The viscosities of these estolides are sufficiently low enough to meet many lubricating applications that the triglyceride estolides from these parent oils could not meet.

Estolides have also been synthesized from 17-hydroxy stearic acid (Zerkowski et. al., 2008) utilizing a protection, deprotection sequence to yield structured estolides. These estolides have exact estolide linkages in terms of both number of oligomers and position. The process will not produce large quantities of material but may shed some insight into the role of linkage position and oligomerization on the resulting physical properties of these novel fluids.

\subsection{Estolides from unsaturated fatty acids}

The next class of estolides is derived from the condensation of a fatty acid across the double bond of a second fatty acid as depicted in Figure 6. Estolides were first identified as minor by-products in the synthesis of dimmer acids using montmorillonite clays as catalysts (Burg and Kleiman 1991) and later synthesized in modest yield (14\%) using a modified version of this batch procedure (Erhan and Kleiman et al., 1993 and Erhan and Isbell 1997), $250^{\circ} \mathrm{C}$ under a 60 psi nitrogen atmosphere over a Montmorillonite K-10 clay catalyst. This work lead to a detailed investigation by Isbell et al., (1994a) and a mechanism for the formation of estolides was explored. Estolides from unsaturated fatty acids were shown to arise from protonation of the double bond to form a carbocation which was subsequently captured by a second fatty acid molecule. Stronger acids with weak nucleophilic conjugate bases gave faster rates of formation and higher yield of estolide. Weak acids like clay only provide 0.04-0.08 mmoles of $\mathrm{H}^{+} / \mathrm{g}$ of clay. In addition, the clay limited the reaction to the formation of monoestolide due to the small intra-spacial dimensions of the layers within the clay which prohibited penetration of estolide

Table 4

Physical properties of lesquerolic and ricinoleic estolide 2-Ethylhexyl esters

\begin{tabular}{|c|c|c|c|c|c|}
\hline $\begin{array}{l}\text { Hydroxy Fatty } \\
\text { Acids }\end{array}$ & Capping Fatty Acids & $\begin{array}{l}\text { Pour Point } \\
\quad\left({ }^{\circ} \mathrm{C}\right)\end{array}$ & $\begin{array}{l}\text { Cloud Point } \\
\left({ }^{\circ} \mathrm{C}\right)\end{array}$ & $\begin{array}{c}\text { Viscosity @ } \\
40^{\circ} \mathrm{C}\end{array}$ & $\begin{array}{c}\text { Viscosity @ } \\
100^{\circ} \mathrm{C}\end{array}$ \\
\hline Hydroxystearic & Acetic & -63 & NA & NA & NA \\
\hline Hydroxystearic & Propanoic & -62 & NA & NA & NA \\
\hline Hydroxystearic & Butanoic & -31 & NA & NA & NA \\
\hline Ricinoleic & Oleic & -54 & $<-54$ & 34.5 & 7.6 \\
\hline Ricinoleic & Stearic & 3 & 23 & 41.7 & 8.6 \\
\hline Ricinoleic & Coconut Fatty Acids & -36 & -30 & 29.0 & 6.5 \\
\hline Ricinoleic & 2-Ethylhexanoic & -51 & $<-51$ & 70.6 & 11.8 \\
\hline Lesquerolic & Oleic & -48 & -35 & 35.4 & 7.8 \\
\hline Lesquerolic & Stearic & 3 & 12 & 38.6 & 8.2 \\
\hline Lesquerolic & Coconut Fatty Acids & -24 & $<-24$ & 40.4 & 8.4 \\
\hline Lesquerolic & 2-Ethylhexanoic & -54 & $<-54$ & 51.1 & 10.1 \\
\hline
\end{tabular}

Estolides synthesized from either castor fatty acids or lesquerella fatty acids as their 2-ehtylhexyl ester. Data summarized from Cermak et. al., (2006) and Teeter et. al., (1953). 
<smiles>CCCCCCC(O)C/C=C/CCCCCCCCCC(=O)OCC(CC)CCCC</smiles><smiles>CCCCCCCCCC(=O)O</smiles><smiles></smiles>

Figure 5

Synthesis of estolides from hydroxy fatty acids.<smiles>CCCCCCCCC=CCCCCCCCC(=O)O</smiles>

Oleic Acid

$\mathrm{H}_{2} \mathrm{SO}_{4}(\mathrm{n}=\mathbf{0 - 3}, 65 \%)$

$\mathrm{HClO}_{4}(\mathrm{n}=0-10,76 \%)$

$p$-Toluenesulfonic $(\mathbf{n}=\mathbf{0 - 3}, \mathbf{4 5 \%})$

Montmorillonite k-10 $(\mathrm{n}=\mathbf{0 - 1}, \mathbf{1 0 - 3 0 \%})$

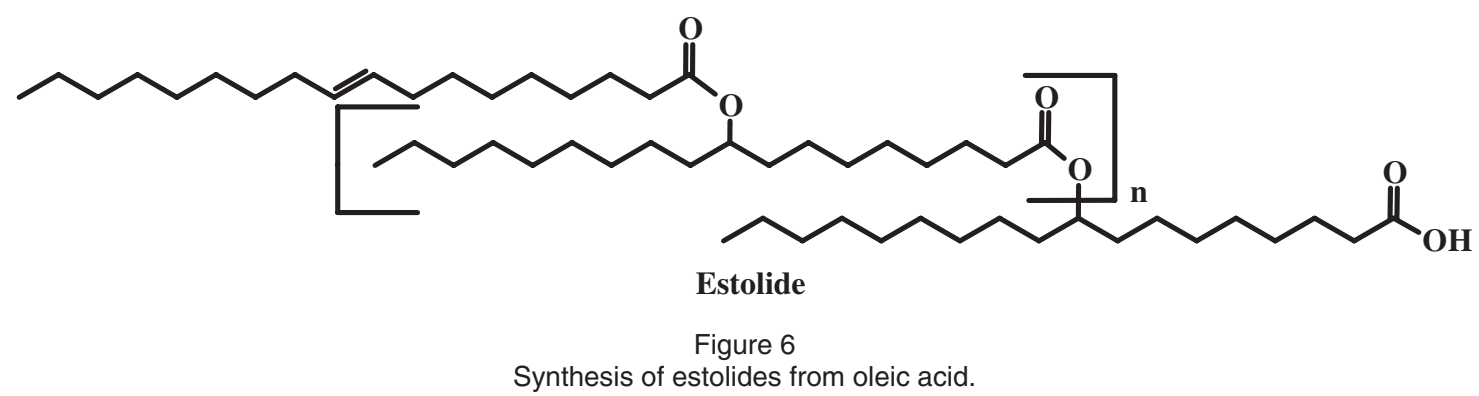

and subsequent formation of higher oligomers. In the best cases, activated clays with increased $\mathrm{H}_{+}$ activity could produce estolide yields up to $41 \%$.

Stronger mineral acids like sulfuric and perchloric with relatively weak nucleophilic conjugate bases gave rapid rates of estolide formation in high yield (76\%) with considerable formation of polyestolide (Isbell et. al., 1994a and Isbell and Kleiman 1994b). These acid catalyzed reactions had EN values of
2.65 with oligomers as high as 11 . Weaker acids like $p$-toluenesulfonic acid had EN values up to 4 . The stronger acids clearly stabilize the carbocation on the fatty acid molecule and provide an opportunity for the condensation reaction into estolide to proceed. Side products of the reaction are lactones, positionally and geometrically isomerized monounsaturated fatty acids. Table 5 outlines a few of many reactions that produced estolide. Sulfuric acid reactions (Isbell et. 
Table 5

Synthesis of estolides from oleic acid

\begin{tabular}{|c|c|c|c|c|}
\hline Acid Catalyst & Catalyst Equiv. & $\begin{array}{c}\text { Temperature } \\
\left({ }^{\circ} \mathrm{C}\right)\end{array}$ & Reaction Time (h) & Yield (\%) \\
\hline $\mathrm{HCLO}_{4}$ & 1.0 & 50 & 2 & 70 \\
\hline $\mathrm{HCLO}_{4}$ & 0.05 & 60 & 24 & 78 \\
\hline $\mathrm{H}_{2} \mathrm{SO}_{4}$ & 1.0 & 50 & 6 & 60 \\
\hline $\mathrm{H}_{2} \mathrm{SO}_{4}$ & 3.3 & 55 & 24 & 80 \\
\hline$p$-Toluene sulfonic acid & 1.0 & 100 & 24 & 45 \\
\hline $\mathrm{BF}_{3}-\mathrm{Et}_{2} \mathrm{O}$ & $1.4 \mathrm{wt} \%$ & 50 & 168 & 71 \\
\hline Montmorillonite K-10 Clay & $20 w t \%$ & 150 & 118 & 41 \\
\hline
\end{tabular}

Data summarized from Isbell et. al., (1994).

al., 1997) gave good yields of estolide but require higher acid equivalents to achieve good reaction rates. Unfortunately, small amounts of sulfonated fatty acids remain unquenched in the estolide products and their decomposition in the product over time can generate very acidic species that are detrimental to estolide performance. The perchloric acid catalyzed reaction can be run at extremely low equivalents, yet maintain reasonable reaction rates with good estolide yield. These estolides do not suffer from catalyst addition products and remain stable over very long periods of time.

The formation of estolides has been demonstrated in other monounsaturated fatty acids as well; meadowfoam, crambe and oleic acids (Isbell and Kleiman 1996; Isbell et al., 2001). The synthesis of meadowfoam estolide was challenged by the formation of the ring closure product $\delta$-Lactone, which is a very competitive reaction path due to the close proximity of the carboxylic functionality of the 5-eicosenoic acid found in this seed oil. Low equivalents of perchloric acid and lower temperatures favored estolide formation where higher acid equivalents and temperature favor lactone formation. These estolides have found a number of uses in the area of cosmetics (Awang et al., 2007b; Isbell et. al., 2000).

The melting point, pour points and viscosity data are reported by Isbell et al. (2001) for a series of estolide esters from crambe, meadowfoam and oleic acids. A subset of this data is shown in Table 6 . The oleic estolide series had the best melting points of all those studied and the branched alkyl esters of the estolide further improved upon these

Table 6

Physical properties of estolide esters

\begin{tabular}{lccc}
\hline \multicolumn{1}{c}{ Estolide } & $\begin{array}{c}\text { Melting Point } \\
\left({ }^{\circ} \mathbf{C}\right)\end{array}$ & $\begin{array}{c}\text { Viscosity @ 40 } \\
\text { (cSt) }\end{array}$ & $\begin{array}{c}\text { Viscosity @ 100 } \\
\text { (cSt) }\end{array}$ \\
\hline Crambe estolide & 0 & 679.0 & 58.6 \\
Crambe estolide 2-ethylhexyl ester & -12 & 184.4 & 26.1 \\
Meadowfoam estolide & 6 & 229.8 & 27.4 \\
Meadowfoam estolide 2-ethylhexyl ester & -1 & 104.2 & 16.5 \\
Oleic estolide & -31 & 404.9 & 40.0 \\
Oleic estolide methyl ester & -27 & 169.1 & 23.7 \\
Oleic estolide butyl ester & -27 & 238.4 & 30.3 \\
Oleic estolide decyl ester & -10 & 149.0 & 21.4 \\
Oleic estolide oleyl ester & -22 & 187.2 & 26.8 \\
Oleic estolide 2-methylpropyl ester & -32 & 200.7 & 26.7 \\
Oleic estolide 2-ethylhexyl ester & -34 & 161.2 & 22.5 \\
Oleic estolide C18 Guerbet ester & -43 & 206.6 & 27.4 \\
Oleic estolide C24 Guerbet ester & -32 & 169.4 & 24.3 \\
\hline
\end{tabular}

Data summarized from Isbell et. al., (2001). 
low temperature properties. Oleic estolide had a melting point of $-31^{\circ} \mathrm{C}$ and upon esterification with a C18 Guerbet alcohol was improved to $-43^{\circ} \mathrm{C}$. Although the Guerbet esters had better low temperature properties the cost associated with production of these alcohols makes this a very expensive ester. In light of these cost issues, the inexpensive 2-ethylhexyl ester provided good low temperature properties and was later used to make a variety of esters from estolides for use in lubricant applications.

The position of the estolide has a pronounced effect on its physical properties. Crambe estolide positions are centered around the original $\Delta 13$ olefin, meadowfoam around $\Delta 5$ and oleic around $\Delta 9$ with melting points of $0^{\circ} \mathrm{C}, 6^{\circ} \mathrm{C}$ and $-31^{\circ} \mathrm{C}$ respectively. This melting point trend suggests that estolides with mid-chain linkages will provide better low temperature properties. As expected, molecular weight also impacts low temperature properties with higher molecular weight molecules yielding higher pour points. Table 7 reports this effect where estolides of increasing estolide number showed an increase in pour point temperatures and monoestolide gave the lowest pour point of $-42^{\circ} \mathrm{C}$ for an oleic estolide 2-ethylhexyl ester. However, when these molecules iodine values were set equal by hydrogenation the impact on pour point was greatly diminished suggesting the composition of the last fatty group to form the estolide may be the most important on the overall physical properties of the molecule.

The capping fatty acid of the estolide was evaluated for the impact of chain length on pour points (Cermak and Isbell 2001; Cermak and Isbell 2002; Cermak and Isbell 2009). Table 8 provides a summary of the work by Cermak and Isbell (2002) which demonstrated that a decanoyl capping group for the estolide provided the lowest pour points within this series. This would be consistent with the concept that the length of the fatty acid capping group should completely reach the terminus of the oleic estolide but not extend beyond the end or fall significantly short of the methyl terminus. When these chain-length requirements are met, intermolecular stacking interactions are prevented and crystal formation inhibited. These molecules have very low iodine values yet have excellent pour point values thereby contradicting the general trend observed for fats that correlate low iodine values with high pour points. As a result of reducing the unsaturation in the molecule, estolides and particularly saturate capped estolides have

Table 7

Effect of oleic estolide oligomerization on physical properties

\begin{tabular}{lcccc}
\hline \multicolumn{1}{c}{ Estolide } & EN \# & $\begin{array}{c}\text { Pour Point } \\
\left({ }^{\circ} \mathbf{C}\right)\end{array}$ & $\begin{array}{c}\text { Viscosity @ } \\
\mathbf{4 0} \mathbf{C}(\mathbf{C S t})\end{array}$ & lodine Value \\
\hline \#1 2-EH ester & 3.0 & -3 & 292.8 & 16.2 \\
\#2 2-EH ester & 2.3 & -27 & 133.2 & 30.5 \\
\#3 2-EH ester & 1.1 & -42 & 43.1 & 52.5 \\
Hydrogenated \#1 2-EH ester & 3.0 & 6 & 285.6 & 2.4 \\
Hydrogenated \#2 2-EH ester & 2.3 & -15 & 139.9 & 3.6 \\
Hydrogenated \#3 2-EH ester & 1.1 & -9 & 48.8 & 2.2 \\
\hline Data summarized from Isbell et. al., (2001). & & &
\end{tabular}

Table 8

Effect of capping fatty acid chain length on oleic estolide physical properties

\begin{tabular}{ccccc}
\hline $\begin{array}{c}\text { Capping Fatty } \\
\text { Acid }\end{array}$ & Pour Point $\left({ }^{\circ} \mathbf{C}\right)$ & Cloud Point $\left({ }^{\circ} \mathbf{C}\right)$ & $\begin{array}{c}\text { Viscosity @ } \mathbf{4 0}{ }^{\circ} \mathbf{C} \\
(\mathbf{C S t})\end{array}$ & $\begin{array}{c}\text { Viscosity @ 100 } \\
(\mathbf{C S t})\end{array}$ \\
\hline 4 & -30 & -36 & 125.5 & 19.3 \\
6 & -30 & -34 & 114.5 & 17.9 \\
8 & -36 & -41 & 104.4 & 16.8 \\
10 & -39 & $\mathrm{NA}$ & 93.8 & 15.5 \\
12 & -36 & -32 & 73.9 & 13.0 \\
14 & -25 & -22 & 80.5 & 13.9 \\
16 & -12 & -13 & 81.6 & 13.5 \\
18 & -5 & -4 & 81.8 & 14.0 \\
\hline
\end{tabular}

Data summarized from Cermak and Isbell (2002). 
good oxidative stability (Cermak and Isbell 2003b; Biresaw et al., 2007; Cermak et al., 2008). Table 9 summarizes the oxidative performance of oleic estolide 2-ethylhexyl esters with coco-oleic estolide 2-ethylhexyl esters. When a commercial antioxidant package supplied by Lubrizol Corp is used the estolide exhibits good oxidative performance. Typical fully formulated commercial crankcase oils have RPVOT values of $\sim 240$ minutes. The unformulated estolide, like most all bio-based materials, has a short life span in this test. Even heavily formulated vegetable oils have difficulty reaching 100 minutes in this rigorous method. However, the estolides with reduced iodine values can be easily formulated to exceed petroleum oxidative stability standards and even perform at levels suitable for hydraulic fluids and aviation lubricants (Cermak and Isbell 2003a; Cermak and Isbell 2004a; Cermak and Isbell 2004b; Cermak et. al., 2007).

Initial film forming properties have recently been examined (Biresaw et al., 2007) for the oleic based estolides including the saturate-capped estolides. The studies indicated that estolides have improved film forming properties when compared to underivatized vegetable oils but perform at a nearly equal level to poly alpha olefins. The mixed estolides had better film properties then the homooligomeric materials. Additional wear studies by Kurth et al., (2007) demonstrated that oleic estolides had good coefficient of friction (COF) properties and the oleic estolide had the lowest COF of the series of simply fatty esters to which it was compared. Kurth's study provided some degree of correlation of the molecular size to the possibility that the molecule would provide multiple sites for adsorption to a metal surface, thus better lubricity. The oleic estolide was the largest molecule in the study and provided the greatest lubricity.

\subsection{Estolides from epoxy fatty acids}

The last class of estolides to discuss is derived from the ring opening of epoxy esters as shown in Figure 7. The epoxide functionality provides a ready handle to conduct a ring opening reaction which is catalyzed insitu by the capping fatty acid and a subsequent condensation with the capping group to form an $\alpha$-hydroxy estolide. Pages and Alfos (2001) report a facile synthesis of epoxidized sunflower methyl esters in a neat reaction with oleic acid and report complete formation of estolide. Awang et al., (2007a) ring open epoxystearic acid to the dihydroxystearic acid and homopolymerize the dihydroxy acid under a nitrogern atmosphere at $180^{\circ} \mathrm{C}$. Awang provides a characterization of the estolides formed and demonstrates that control of the reaction time can control the extent of oligomerization. Awang's study also observes the synthesis of oligomers up to an EN = 5 under these reaction conditions after a reaction time of 8 hours. Moser et al., (2007) ring open epoxystearate esters by reacting propyl or octyl epoxystearate with a series of fatty acids (propanoic, 2-propanoic, octanoic and 2-ethylhexanoic) to form $\alpha$-hydroxy estolides. The resulting $\alpha$-hydroxy estolides were evaluated for cold temperature properties and oxidative stability. The estolide reported to have the best cold temperature properties within the above mentioned series was the propyl ester of an $\alpha$-hydroxy, 2-ethylhexyl estolide with a pour point of $-39^{\circ} \mathrm{C}$.

\section{CONCLUSIONS}

Estolides are novel derivatives of fats that have good physical properties and they are starting to demonstrate usefulness within their own right.

Table 9

Oxidative stability of oleic based estolides by RPVOT

\begin{tabular}{ccccc}
\hline Additive $^{\text {a }}$ & \% Additive & Ratio BHT:ADA & $\begin{array}{c}\text { RPVOT for Oleic } \\
\text { Estolide 2-EH } \\
\text { Ester (min) }\end{array}$ & $\begin{array}{c}\text { RPVOT Coco- } \\
\text { Oleic Estolide } \\
\text { 2-EH Ester (min) }\end{array}$ \\
\hline None & 0 & NA & 8 & 17 \\
Lubrizol-7652 & 0.5 & NA & 50 & 113 \\
Lubrizol-7652 & 1.0 & NA & 132 & 245 \\
Lubrizol-7652 & 2.0 & NA & 274 & 431 \\
BHT:ADA & 1.0 & $100: 0$ & 99 & 115 \\
BHT:ADA & 1.0 & $75: 25$ & 150 & 185 \\
BHT:ADA & 1.0 & $50: 50$ & 209 & 251 \\
BHT:ADA & 1.0 & $25: 75$ & 226 & 281 \\
BHT:ADA & 1.0 & $0: 100$ & 248 & 326 \\
\hline
\end{tabular}

Data from Cermak et. al., (2008). ${ }^{\mathrm{a}} \mathrm{BHT}$ is butyl hydroxy toluene and ADA is alkylated diphenylamine. 


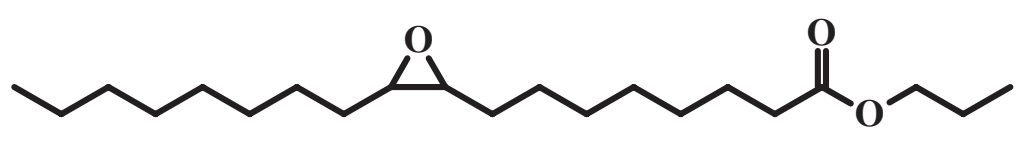

Propyl 9,10-epoxystearate

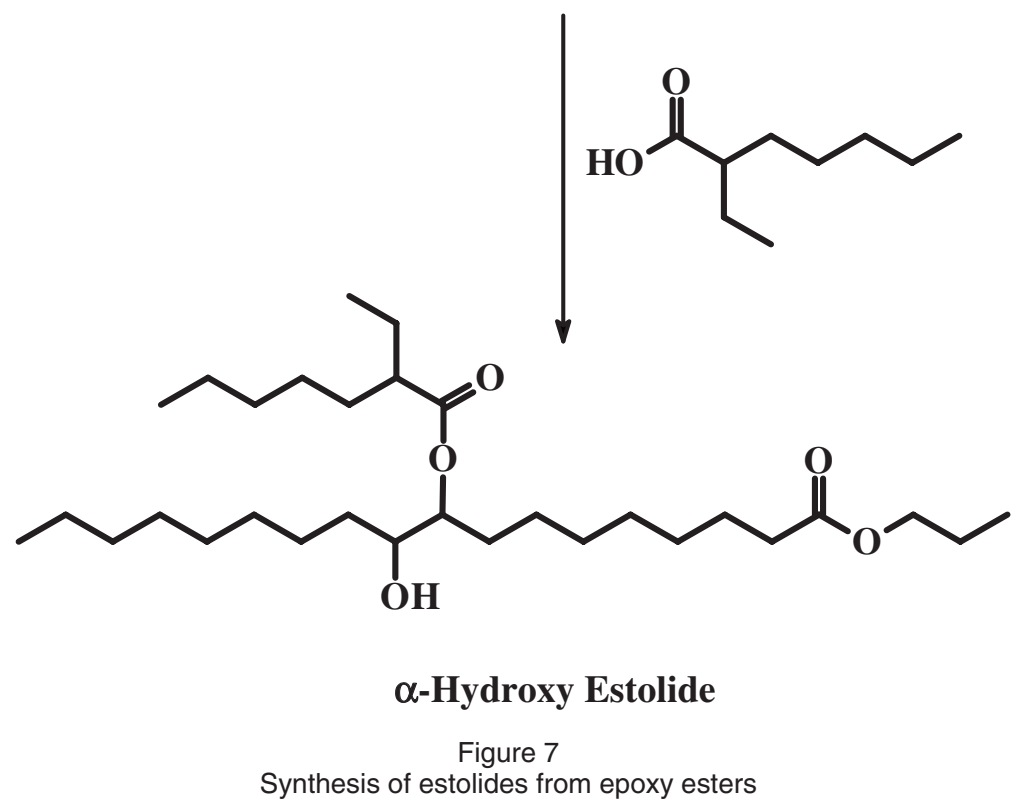

Estolides from hydroxy containing fats are the simplest to synthesize. Triglyceride estolides of castor and lesquerella have demonstrated decent performance for their low temperature properties but need additional effort to improve their poor oxidative performance. Free acid estolides from both hydroxy containing fatty acids and unsaturated fatty acids show real promise as base stocks for a wide range of lubricant applications. Their excellent cold temperature properties coupled with their good oxidative stability should see these derivatives in many industrial applications. Synthesis of estolides from unsaturated fatty acids opens the possibility of making estolides with wide ranging physical properties based on their point of linkage and extent of oligomerization. Estolides from unsaturated fatty acid sources are only limited by the availability of novel olefin positions.

\section{ACKNOWLEDGMENTS}

The author thanks Dr. Joaquín Salas for the invitation to submit this manuscript. A special thanks to all the authors cited in this review and their hard work directed toward the development of estolides, and in many cases also to their effort to introduce new crops.

\section{REFERENCES}

Aitzetmuller K, Xin Y, Werner G, Margaretha G. 1992. High performance liquid chromatographic investigations of stillingia oil. J. Chromr. 603, 165-173.
Awang R, Azizan AB, Ahmad S, Ahmad N, Yunus WNZW. 2007a. Characterization of estolides from dihydroxystearic acid. J. Oil Palm Res. 19,350-355.

Awang R, Azizan AB, Ahmad S, Yunus WNZW, Ahmad N. 2007b. Palm-Based estolide as an ingredient in shampoo: A preliminary study. J. Oil Palm Res. 19,416-420.

Biresaw G, Cermak SC, Isbell T A. 2007. Film-forming properties of estolides. Tribology Letters, 27, 69-78.

Cermak SC, Isbell TA. 2001. Synthesis of estolides from oleic and saturated fatty acids. J. Am. Oil Chem. Soc. 78, 557-565.

Cermak SC, Isbell TA. 2002. Physical properties of saturated estolides and their 2-ethylhexyl esters. Ind. Crops and Prod. 16, 119-127.

Cermak SC, Isbell TA. 2003a. Synthesis and physical properties of estolide-based functional fluids. Ind. Crops and Prod. 18, 183-196.

Cermak SC, Isbell TA. 2003b. Improved oxidative stability of estolide esters. Ind. Crops and Prod. 18, 223-230.

Cermak SC, Isbell TA. 2004a. Synthesis and Physical Properties of Cuphea-Oleic Estolides and Esters. J. Am. Oil Chem. Soc. 81, 297-303.

Cermak, SC, Isbell TA. 2004b. Estolides-The next biobased functional fluid. Inform 15, 515-517.

Cermak SC, Brandon KB, Isbell TA. 2006. Synthesis and physical properties of estolides from lesquerella and castor fatty acid esters. Ind. Crops and Prod. 23, 54-64.

Cermak SC, Skender AL, Deppe AB, Isbell TA. 2007. Synthesis and physical properties of tallow-oleic estolide 2-ethylhexyl esters. J. Am. Oil Chem. Soc. 84, 449-456.

Cermak, SC, Biresaw G, Isbell TA. 2008. Comparison of a new Estolide oxidative stability package. J. Am. Oil Chem. Soc. 85, 879-885.

Cermak SC, Isbell TA. 2009. Synthesis and physical properties of mono-estolides with varying chain lengths. Ind. Crops and Prod. 29, 205-213. 
Erciyes AT, Dandik L, Kabasakal OS. 1991. The kinetics of the esterification reaction between castor oil and oleic acid. J. Am. Oil Chem. Soc. 68, 639-641.

Erdem-Senatalar A, Erencek $\mathrm{E}$, Tüter $\mathrm{M}$, Erciyes AT. 1994. Effect of Lewis acid catalysts on the esterification kinetics of castor oil with oleic acid. J. Am. Oil Chem. Soc. 71, 1035-1037.

Erdem-Senatalar A, Erencek E, Erciyes AT. 1995. Mechanism and Kinetics of the $\mathrm{COCl}_{2}$-catalyzed esterification reaction of castor oil with oleic acid. $\mathrm{J}$. Am. Oil Chem. Soc. 72, 891-894.

Erhan SM, Kleiman R, Isbell TA. 1993. Estolides from meadowfoam oil fatty acids and other monounsaturated fatty acids. J. Am. Oil Chem. Soc. 70, 461-465.

Erhan SM, Isbell TA. 1997. Estolide production with modified clay catalysts and process conditions. J. Am. Oil Chem. Soc. 74, 249-254.

Hayes DG, Kleiman R, Phillips BS. 1995a. The triglyceride composition, structure, and presence of estolides in the oils of lesquerella and related species. J. Am. Oil Chem. Soc. 72, 559-569.

Hayes DG and Kleiman R. 1995b. Lipase-catalyzed synthesis and properties of estolides and their esters. J. Am. Oil Chem. Soc, 72, 1309-1316.

Hayes DG. 1996. The catalytic activity of lipases toward hydroxy fatty acids - A review. J. Am. Oil Chem. Soc. 73, 543-549.

Isbell TA, Kleiman R, Plattner BA. 1994a. Acid catalyzed condensation of oleic acid into estolides and polyestolides. J. Am. Oil Chem. Soc. 71, 169-174.

Isbell TA, Kleiman R. 1994b. Characterization of estolides produced from the acid-catalyzed condensation of oleic acid. J. Am. Oil Chem. Soc. 71, 379-383.

Isbell TA, Kleiman R. 1996. Mineral acid-catalyzed condensation of meadowfoam fatty acids into estolides. J. Am. Oil Chem. Soc. 73, 1097-1107.

Isbell TA, Frykman HB, Abbott TP, Lohr JE. 1997. Optimization of the sulfuric acid-catalyzed estolide synthesis from oleic acid. J. Am. Oil Chem. Soc. 74, 473-476.

Isbell TA, Abbott TP, Dworak JA. 2000. Shampoos and conditioners containing estolides U.S. Patent $6,051,214$

Isbell TA, Edgcomb MR, Lowery BA. 2001. Physical properties of estolides and their ester derivatives. Ind. Crops and Prod. 13, 11-20.

Isbell T A, Cermak SC. 2002. Synthesis of triglyceride estolides from lesquerella and castor oils. J. Am. Oil Chem. Soc., 79, 1227-1233.
Isbell TA, Lowery BA, DeKeyser SS, Winchell ML, Cermak SC. 2006. Physical properties of triglyceride estolides from lesquerella and castor oils. Ind. Crops and Prod. 23, 256-263.

Kiatsimkul P, Suppes GJ, Hsieh F, Lozada Z, Tu Y. 2008. Preparation of high hydroxyl equivalent weight polyols from vegetable oils. Ind. Crops and Prod. 27, 257-264.

Kleiman R, Spencer GF, Earle FR, Nieschlang HJ. 1972. Tetra-acid triglycerides containing new hydroxy eicosadienoyl moiety in Lesquerella auriculata seed oil. Lipids 7, 660-665.

Kurth TL, Byars JA, Cermak SC, Sharma BK, Biresaw, G. 2007. Non-linear adsorption modeling measurements. Wear 262, 536-544.

Lawate, SS. 1995. Triglyceride oils thickened with estolides of hydroxy-containing triglycerides. U.S. Patent 5, 427,704.

Meyer, H. 1897. Arch. Pharm. 237, 184.

Modak SN, Kane JG. 1965. Studies in estolides. I. kinetics of estolide formation and decomposition. $J$. Am. Oil Chem. Soc. 42, 428-432.

Moser BR, Sharma BK, Doll KM, Erhan SZ. 2007. Diesters from oleic acid: Synthesis, low temperature properties and oxidation stability. J. Am. Oil Chem. Soc. 84, 675-680.

Pages X, Alfos C. 2001. Synthesis of new derivatives from vegetable sunflower oil methyl ester via epoxidation and oxirane opening. Oleagineux Crops gras Lipides 8, 122-125.

Payne-Wahl K, Kleiman R. 1983. Quantitation of estolide triglycerides in Sapium seeds by high performance liquid chromatography with infrared detection. J. Am. Oil Chem. Soc. 60, 1011-1012.

Penoyer, CE, Fischer, W, Bobalek, EG. 1954. Synthesis of drying oils by thermal splitting of secondary fatty acid esters of castor oil. J. Am. Oil Chem. Soc. 31, 366-370.

Platner RD, Payne-Wahl K, Tjarks, LW. 1979. Hydroxy acids and estolide triglycerides of Heliophila amplexicaulis L.f. Seed Oil. Lipids 14, 576-579.

Teeter HM, Gast LE, Bell EW, Cowan JC. 1953. Synthetic lubricants from hydroxystearic acids. Ind. Eng. Chem. 45, 1777-1779.

Zerkowski JA, Nunez A, Solaiman DKY. 2008. Structured estolides: Control of length and sequence. J. Am. Oil Chem. Soc 85, 277-284.

Recibido: $12 / 1 / 10$ Aceptado: 25/1/10 